\title{
A literatura menor em Deleuze e Guattari: por uma educação menor
}

\author{
Minor literature on Deleuze and Guattari: for a minor education
}

Francis Mary Soares Correia da Rosa* Universidade Estadual de Feira de Santana

Resumo Trata-se de uma investigação sobre o conceito deleuze-guattariano de literatura menor e suas implicâncias na esfera educacional brasileira elaborados na obra do filósofo brasileiro Silvio Gallo. Para Gallo, deslocar as características da literatura menor para o campo educacional significa uma reelaboração da própria atividade docente ao lançar na questão da prática diária do professor e com a própria instituição escolar uma atividade iminentemente política. De acordo com Gallo este é o alicerce da prática de uma educação menor que está em contraponto direto ao que poderia ser caracterizado como uma educação maior, cujo campo de constituição ocorreria nos tramites estatais, das políticas públicas da educação, dos ordenamentos e dispositivos curriculares. Espera-se nesse artigo rastrear as possibilidades e deslocamentos que tal conceito promove na prática educativa.

PALAVRAS-CHAVE: Deleuze; Gallo; Educação.

Abstract This is an investigation into the deleuze-guattarian concept of minor literature and its implications in the Brazilian educational sphere developed in the Brazilian philosopher Silvio Gallo work. For Gallo, move older literature characteristics for the educational field means a reworking of his own teaching activity to launch the issue of the daily practice of the teacher and the school institution itself an imminently political activity. According to Gallo, this is the foundation of practice lower education in direct opposition to what might be a higher education, whose constitution field occur in state formalities, public policy education and legal systems and curricular devices. It is hoped this article to trace the possibilities and shifts that this concept promotes the educational practice.

KEYWORDS: Deleuze; Gallo; Education. 


\section{Introdução}

Uma das marcas mais importantes da filosofia deleuze-guattariana é a criação conceitual. Para os filósofos franceses é por meio da atividade que violenta o pensamento e que produz deslocamentos que é possível produzir o novo. Dessa forma, o sistema filosófico produzido por Gilles Deleuze de forma individual e mesmo aquilo que escreveu em parceria com o psicanalista Félix Guattari se constitui como uma "caixa de ferramentas" que mobiliza a atividade criativa por meio do conceito.

Considerar o conceito como própria natureza do acontecimento e da experimentação implica, para Deleuze, observá-lo como algo mutável e atrelado à natureza das circunstancias da própria criação conceitual, pois o conceito implica a própria natureza do devir, ele não é algo dado, pronto ou acabado, mas a solução a um problema posto ao pensamento. Sobre isso, escreve Deleuze: "[...] a única condição é que eles tenham uma necessidade, como também uma estranheza, e eles as têm na medida em que respondem a verdadeiros problemas" (DELEUZE, 2000, p. 170).

Em contraponto à filosofia que somente reproduz ou busca identidade, os autores franceses defendem uma filosofia engajada na criatividade, na produção conceitual como tarefa do filósofo. Por o pensamento em movimento por meio da atividade da criação conceitual. Nas palavras David Lapoujade, conceituado comentador da obra de Gilles Deleuze na França: "A filosofia de Deleuze se apresenta como uma filosofia dos movimentos aberrantes ou dos movimentos 'forçados'" (LAPOUJADE, 2015, p. 9).

Por meio disto, objetivamos nesse artigo oferecer uma revisão bibliográfica de um dos conceitos que mais proliferou deslocamentos no cenário da educação nacional, a saber, o conceito de literatura menor. Traçaremos o viés conceitual produzido pelos próprios autores de forma prioritária na obra Kafka: por uma literatura menor e nos desdobramentos de tal conceito na obra do filósofo brasileiro Silvio Gallo, no que tange ao que ele sistematizou como uma pedagogia menor. Diante disso, construiremos um ponto de partida na obra deleuziana, porém seu ponto de contato será sempre como movimento aberrante imbricado a uma necessidade própria, nunca tentativa de reprodução.

\section{Menor/Maior em Deleuze e Guattari: caminhos da menoridade literária}

Na obra dos filósofos franceses Felix Guattari e Gilles Deleuze (2002) as noções de "menor/maior" ganham destaque como ferramentas conceituais abertas a experimentações. Diante dessa última afirmação, é imprescindível perceber o movimento presente em qualquer aproximação que se possa fazer com essa "caixa de ferramentas conceitual", visto que não é aplicação simples e pura, pois o conceito é fugidio. A proposta de compreender a experimentação como algo criativo envolve a própria alternativa deleuziana para oferecer uma nova forma de pensar, pois ainda: "Pensar é sempre experimentar, não interpretar, mas experimentar, e a experimentação é sempre o atual, o nascente, o novo, o que está em vias de se fazer." (DELEUZE, 1992, p. 136). 
Nesse sentido, experimentar está no limite entre o dado e o novo, pois para Deleuze o pensar não está desassociado da experiência (ou exclusivamente depende dela), antes mesmo, é por meio dessa que é possível superar o dado ou hábito e criar algo novo, retirar o pensamento da zona familiar e impor-lhe uma violência criadora, "[..] e o que se há de pensar é do mesmo modo o impensável ou o não pensado" (DELEUZE, 2000, p. 143).

Em meio a este aspecto, é preciso salientar que menor/maior não se definem pelo contingente numérico. Para Deleuze e Guattari (1995), a menoridade de algo é reflexível na sua apresentação como diferença e pluralidade frente ao que se estabelece como padrão e norma, propondo uma dobra na natureza do que é fixado e que se apresenta como identidade. Nesse sentido, a maioridade é condição de existência de uma dada menoridade.

\begin{abstract}
A noção de minoria, com suas remissões musicais, literárias, linguísticas, mas também jurídicas, políticas, é bastante complexa. Minoria e maioria não se opõem apenas de uma maneira quantitativa. Maioria implica uma constante, de expressão ou de conteúdo, como um metro padrão em relação ao qual ela é avaliada. Suponhamos que a constante ou metro seja homem-branco-masculino-adulto-habitante das cidades-falante de uma língua padrão-europeu-heterossexual qualquer (o Ulisses de Joyce ou de Ezra Pound). É evidente que 'o homem' tem a maioria, mesmo se é menos numeroso que os mosquitos, as crianças, as mulheres, os negros, os camponeses, os homossexuais... etc. $\hat{E}$ porque ele aparece duas vezes, uma vez na constante, uma vez na variável de onde se extrai a constante. A maioria supõe um estado de poder e de dominação, e não o contrário. Supõe o metro padrão e não o contrário. (DELEUZE; GUATTARI, 1995, p. 55).
\end{abstract}

Pensar a menoridade literária na obra deleuze-guattariana, tal como proposto nesse artigo é situa-la como contrassenso e contra discurso não somente no campo literário, mas na expressão política de sua obra. Para Deleuze (1998), o objetivo da escrita é afirmar sua própria impessoalidade e por meio desta última, conjugar-se em fluxo a todos os devires-minoritários do mundo. Nesse aspecto, há determinadas literaturas que se apresentam como agenciamento, pluralizando linhas de fuga que promovem a criação desses devires, produzindo multiplicidades e efeitos, movimentando-se no seu devir. São como tocas ${ }^{1}$, cheias de entradas. Seus personagens são sempre imagens de desterritorialização, criando fluxos e desfazendo significações.

Tal perspectiva nos coloca diante de uma escrita potencializada de devir e com caráter minoritário: uma literatura menor. Consagrado no livro de Gilles Deleuze "Kafka: Por uma literatura menor", escrito em conjunto com o psicanalista Félix Guattari, o termo remonta sua origem a obra do próprio Franz Kafka. Segundo Dirk Weissmann (2012), é ao falar sobre os escritos em língua iídiche na cidade de Praga que Kafka ${ }^{2}$ caracteriza e enaltece a presença destas "pequenas literaturas" (die kleinen Literaturen em alemão). É na tradução do diário de Kafka para a língua francesa, feita por Marthe Robert em 1950, que aparece pela primeira vez a expressão "petites littératures" já apontando, segundo Weissmann (2012), um tom valorativo na expressão utilizada pela tradutora ao oferecer aproximação de sentidos entre "klein" considerado 
apenas descritivo no alemão e "petite" que possui um tom mais pejorativo no francês ${ }^{3}$. Para além de uma discussão sobre as origens, é necessário apontar que o conceito ganha um arranjo decisivo na obra de Gilles Deleuze e Felix Guattari, publicada pela primeira vez em 1975, Kafka: Por uma literatura menor.

Esta obra se responsabiliza por popularizar o termo no meio acadêmico, ao mesmo tempo que evidência seu poder de circulação e sua natureza subversiva, propondo uma inversão de natureza qualitativa na tradução de Marthe Robert: o menor (petite), outrora de dimensão negativa, é transvalorado como algo desejável e portador de devir (WEISSMANN, 2013).

Segundo Deleuze e Guattari (2002, p.41): "As três características da literatura menor são de desterritorialização da língua, a ramificação do individual no imediato político, agenciamento coletivo de enunciação". De acordo com os autores supracitados, a conceitualização de uma "literatura menor" não se restringe a produção escrita em uma língua dita "menor". A menoridade literária ocorre no desarranjo desterritorializante promovido pela construção no uso da língua que uma minoria faz em uma língua maior. Esse caráter desterritorializante lança a língua maior em processo de fuga, desterritorializando seus usos dentro dos ordenamentos discursivos.

Na perspectiva deleuziana o conceito de território vai além da simples visão etológica e mostra-se filosófica, geográfica, histórica e psicológica. Esta constituição de território se estabelece como o espaço do sujeito no mundo, a representação do seu desejo ${ }^{4}$. Todos os seres constituiriam territórios se articulando sempre com os movimentos que os fazem se colocar fora deles, daí territorialização e desterritorialização constituírem um fluxo cósmico de entradas e saídas de territórios, fazendo parte um do outro.

\begin{abstract}
Jamais nos desterritorializamos sozinhos, mas no mínimo com dois termos: mão-objeto de uso, boca-seio, rosto-paisagem. E cada um dos dois termos se reterritorializa sobre o outro. De forma que não se deve confundir a reterritorialização com o retorno a uma territorialidade primitiva ou mais antiga: ela implica necessariamente um conjunto de artifícios pelos quais um elemento, ele mesmo desterritorializado, serve de territorialidade nova ao outro que também perdeu a sua. (DELEUZE, 1999, p.37.)
\end{abstract}

Nesse sentido, a desterritorialização de uma língua maior ocorre por meio do uso "desobediente" que um grupo promove em meio a língua padrão, formal, uma língua que congrega os ordenamentos e poderes do discurso. Ao deslocar o uso, ao propor outros agenciamentos ocorre um processo de desterritorialização, ao mesmo tempo que territorializa um outro território. $\mathrm{O}$ agenciamento é uma expressão da multiplicidade e efetuação do desejo, de caráter heterogêneo e que se apresenta por meio das relações possíveis entre termos de naturezas distintas (DELEUZE; PARNET, 1998, p.83). Para além das configurações das relações de força que compõem o campo social, o agenciamento é inserção de uma irregularidade disjuntiva nos alicerces do poder.

A unidade real mínima não é a palavra, a ideia ou o conceito; nem o significante, mas o agenciamento. É sempre um agenciamento que produz os enunciados. Os enunciados não têm por causa um 
sujeito que agiria como sujeito da enunciação, principalmente porque eles não se referem aos sujeitos como sujeitos do enunciado. $\mathrm{O}$ enunciado é o produto de um agenciamento, sempre coletivo, que põe em jogo, em nós e fora de nós, as populações, as multiplicidades, os territórios, os devires, os afetos, os acontecimentos (DELEUZE; PARNET, 1998, p. 65).

Na segunda característica Gilles Deleuze e Félix Guattari (2002, p. 42) alertam para o caráter da "[...] ramificação do individual no imediato político" e enaltecem que tal desdobramento do uso da língua por uma minoria subalternizada, conforme Deleuze e Guattari (2002), se relaciona diretamente ao seu imediato político.

Isso significa possibilitar o entendimento de uma literatura menor como aquela que não se propõe a reprodução de questões de natureza estritamente individual, mas que emerge na proximidade política presente na própria arquitetura e funcionamento do texto. Nesse sentido, o próprio autor sofre processo de desterritorialização, e sua escrita não se refere somente a uma dada natureza na esfera do que é biográfico ou privado, mas na sua possibilidade de encontrar "[...] seu próprio ponto de subdesenvolvimento, seu próprio patoá, seu próprio terceiro mundo, seu próprio deserto (DELEUZE; GUATTARI, 2002, p. 42). Tudo é político em uma literatura menor. E esse imediato político refere-se eminentemente ao enfrentamento e contestação de um estado de coisas ordenado e legitimado como hegemônico.

Nesse sentido, ao destacarem que a terceira característica principal de uma menoridade literária se constitui na sua composição como valor coletivo, Deleuze e Guattari (2002), propõem que o campo político seja a força criativa de todo o enunciado. Isso significa dizer que o "[...] enunciado individual é imediatamente coletivo, e o escritor, na sua individualidade, desde já articula uma ação comum" (SCHOLLHAMMER, 2001, p.63). Se o agenciamento demonstra um caráter individualizante, segundo François Zourabichvili (2009), não é nunca no sentido de pertencer a um sujeito em exclusividade. Mas, na relação que ocorre entre o devir singular de alguém e em seu agenciamento maquínico para uma coletividade.

Há uma figura universal da consciência minoritária, como devir de todo o mundo, e é esse devir que é criação. Não é adquirindo a maioria que se o alcança. Essa figura é precisamente a variação contínua, como uma amplitude que não cessa de transpor, por excesso e por falta, o limiar representativo do padrão majoritário. Erigindo a figura de uma consciência universal minoritária, dirigimo-nos a potências de devir que pertencem a um outro domínio, que não o do Poder e o da Dominação. É a variação contínua que constitui o devir minoritário de todo o mundo, por oposição ao Fato majoritário de Ninguém. (DELEUZE; GUATTARI, 1995, p. 57).

O viés coletivo, como destacado pelos filósofos franceses, perpassa então pelo desaparecimento do autor, naquilo que sua autoria destoa de tudo que é posto como qualidade do "autoral", pois uma tal menoridade literária deve sobretudo agenciar outras vozes e por elas ser atravessada.

Para Gilles Deleuze (2011), a tarefa da literatura é escrever um povo que falta. "Não se escreve com as próprias lembranças, a menos que delas se faça a origem ou a destinação coletivas de um povo por vir ainda enterrado em suas traições e rene- 
gações" (DELEUZE, 2011, p.14). O devir-minoritário é fundamentalmente político e, nesse sentido como salienta David Lapoujade (2015), se constituem como verdadeiras máquinas de guerra do por vir. Isso implica dizer que se está na seara da criação de direitos, pois todo devir-minoritário é invisível e inaudível. Até que se grite!

Essa composição e esfera do por vir na questão do direito possibilita compreender que se está modificando a percepção sobre a própria potência da lei. A justiça é $\operatorname{desejo}^{5}$, e isso reelabora a própria expectativa sobre o direito, a saber, que ele não existe como aparelho que legitima o que existe, mas que opera em "fazer existir o que não tem legitimidade, o que ninguém vê nem ouve, em tomar o partido das multiplicidades imperceptíveis" (LAPOUJADE, 2015, p. 275).

Desse modo, como propõe Karl Schollhammer (2001, p. 64), “[...]o aspecto imediatamente político da literatura menor não tem nada a ver com seu conteúdo ideológico, mas com sua performance enquanto uma multiplicidade de atos de fala que forma uma máquina expressiva”. Assim, o texto literário, as literaturas dissidentes em meio a uma literatura que "se chama grande" (DELEUZE; GUATTARI, 2002, p.42) operam na promoção da audição de outros logos, em um limite, como afirma Deleuze (2011, p.9), que "arrasta a língua para fora de seus sulcos costumeiros, leva-a a delirar".

\section{A menoridade no campo educacional: por uma pedagogia} menor

$\mathrm{Na}$ primeira parte desse artigo observamos como o conceito de literatura menor dos autores franceses Deleuze e Guattari provocam um novo olhar não somente nos estudos literários, mas sobretudo colocam a literatura como uma das formas de deslocamento e rearticulação das esferas políticas e da própria representação dos sujeitos no mundo. É por meio do próprio sistema filosófico dos autores supracitados que encontramos a legitimidade para que a criação conceitual não se transforme em um movimento estanque ou simples decalque. Ao explanar sobre a necessidade da construção de uma nova imagem de pensamento, ou mesmo uma não imagem, Deleuze e Guattari (2007) propõem uma percepção do conceito como uma atividade criadora capaz de retirar o pensamento de sua inércia. Mesmo diante de outros autores e do corpo conceitual criado por estes, a perspectiva das multiplicidades instaurada na atividade da criação conceitual habilitaria espaços para criar novas percepções conceituais e tornar o pensamento criativo. "Todo conceito é ao menos duplo, ou triplo, etc." (DELEUZE, 2007, p. 27).

Por meio disso, o filósofo brasileiro Sílvio Gallo promove um deslocamento do conceito de "literatura menor" para o campo educacional, promovendo uma leitura original não somente da obra deleuze-guattariana, mas também na própria construção de um pensamento filosófico na educação brasileira.

Pretendo, com este artigo, aplicar certos princípios da filosofia trabalhados por Gilles Deleuze à filosofia da educação. Ao fazê-lo, tenho clareza disso, estarei "roubando" conceitos deleuzianos mas, como veremos adiante, no universo deste filósofo o roubo de conceitos é uma atitude extremamente criativa: retomar um conceito 
filosófico é recriá-lo, é dar-lhe novas e antes insuspeitas- às vezes, até mesmo improváveis - significações. Penso que a compreensão que Deleuze - em colaboração com Félix Guattari - construiu da filosofia pode ser de muita valia para pensarmos o sentido e a tarefa da filosofia da educação em nossos dias. (GALLO, 2000, p. 1).

Para Gallo (2013), o deslocamento produzido em meio ao conceito de "literatura menor" permite pensar em uma "educação menor". Nesse sentido, o autor destaca que uma educação menor seria um dispositivo capaz de promover um estranhamento no status quo da educação e da filosofia da educação no Brasil. O autor supracitado destaca que a atividade militante configura a atuação do professor ou professora de uma educação menor. Por "professor militante", de acordo com Gallo (2013, p.61), devemos entender o professor ou professora que se recusa a somente anunciar a possibilidade de algo novo. O professor (a) militante cria as condições para que um campo de possibilidades se instaure.

O professor militante seria aquele que, vivendo com os alunos o nível de miséria que esses alunos vivem, poderia, de dentro desse nível de miséria, de dentro dessas possibilidades, buscar construir coletivamente. Essa é a chave da ação do militante. Sempre uma construção coletiva (GALLO, 2013, p. 61).

Nesse sentido, Gallo (2013) propõe uma reelaboração da própria atividade docente ao lançar na questão da prática diária do professor com seus alunos, colegas, comunidade e a própria instituição escolar uma atividade iminentemente política. De acordo com Gallo (2013), este é o alicerce da prática de uma educação menor que está em contraponto direto ao que poderia ser caracterizado como uma educação maior, cujo campo de constituição ocorreria nos tramites estatais, das políticas públicas da educação e dos ordenamentos e dispositivos curriculares.

Para Silvio Gallo (2013), deslocar as três características da literatura menor para o campo educacional significa pensar em meio ao movimento que o pensamento necessita para produzir algo novo. Nesse sentido, se a primeira característica de uma literatura menor é a desterritorialização da língua, Gallo defende que tal princípio seja pensado no campo educacional como um movimento desterritorializante nos processos educativos, dos dispositivos institucionais e curriculares. Para o autor, a escola pensada em acordo com os parâmetros nacionais e políticas públicas, que são evidentemente normativas, é a escola do controle e da disciplina, no modelo foucaultiano ${ }^{6}$. Essa escola "maior", da norma e do padrão, institucionaliza não somente um currículo nacional, mas também se insere biopoliticamente no campo de produção da própria subjetividade dos sujeitos envolvidos. Cria diretrizes, orientações e representa um projeto hegemônico sobre a identidade dos indivíduos, assim como prioriza certos saberes em detrimento de outros.

Para Tomaz Tadeu da Silva (2010), o currículo não é somente um conjunto aleatório de temas e conteúdos a serem estudados, ele representa uma prática cultural que expressa e dá significado ao projeto político dominante. O currículo, para o autor, é antes de tudo uma aposta e uma disputa ética, moral e política. 
Operar um corte desterritorializante nesta perspectiva, segundo Gallo (2013), seria compor um ato de resistência, de ferocidade frente ao controle e normatização estabelecidos pelo projeto macro político da escola e das instituições governamentais. Um rompimento por dentro, desestabilizando as engrenagens do sistema. Um exemplo pontual deste procedimento poderia ocorrer, por exemplo, por meio da ativação de um currículo oculto nas práticas e atividades do docente.

Tal atividade reativa, segundo Gallo (2013), nos coloca diante de um imperativo das práticas menores, a saber, seu indissociável agenciamento político. Dessa forma, pensar a ramificação política no eixo educacional é pensar a educação e as práticas relacionadas e transpassadas por ela como um ato político.

Uma educação menor evidencia a dupla face do agenciamento: agenciamento maquínico de desejo do educador militante e agenciamento coletivo de enunciação, na relação com os estudantes e com o contexto social. Esse duplo agenciamento produz possibilidades, potencializa os efeitos da militância (GALLO, 2013, p. 67).

Tal perspectiva corrobora no entendimento que uma educação menor, mediante Gallo (2013), se coloca lado a lado com uma micropolítica que se efetua no cotidiano, na relação dos sujeitos envolvidos e suas escolhas éticas e politicamente direcionadas a construir a educação menor como máquina de guerra e não como mais um modelo que logo será internalizado pelo estado.

Para Gilles Deleuze e Felix Guattari (2012), uma máquina de guerra revela-se como plano exterior a todo o aparelho estatal. Isso significa dizer que, para os autores supracitados, a máquina de guerra se apresenta como exterioridade no limite irremediável de sua própria filiação ou proximidade com a forma-Estado. Não é uma exterioridade absoluta, se apresentando mais como uma concorrência em coexistência. A máquina de guerra é fundamentalmente um dispositivo de experimentação, ao nível da criação, que se situa às margens de toda e qualquer estrutura estática do campo social. Seu objetivo não é propriamente a guerra, mas fazer fugir um dado campo estratificado.

A forma-Estado, como forma de interioridade, tem uma tendência a reproduzir-se, idêntica a si através de suas variações, facilmente reconhecível nos limites de seus pólos, buscando sempre o reconhecimento público (o Estado não se oculta). Mas a forma de exterioridade da máquina de guerra faz com que esta só exista nas suas próprias metamorfoses; ela existe tanto numa inovação industrial como numa invenção tecnológica, num circuito comercial, numa criação religiosa, em todos esses fluxos e correntes que não se deixam apropriar pelos Estados senão secundariamente. Não é em termos de independência, mas de coexistência e de concorrência, num campo perpétuo de interação, que é preciso pensar a exterioridade e a interioridade, as máquinas de guerra de metamorfose e os aparelhos identitários de Estado, os bandos e os reinos, as megamáquinas e os impérios. Um mesmo campo circunscreve sua interioridade em Estados, mas descreve sua exterioridade naquilo que escapa aos Estados ou se erige contra os Estados. (DELEUZE; GUATTARI, 2012, p. 25). 
Para Osmar Moreira (2014, p.175), a constituição de uma máquina de guerra é uma investida que incorre numa atitude de crítica frente, entre outras coisas, a toda e qualquer "[...] noção de cultura que se quer hegemônica", projetando um estado de devir na própria subjetividade dos sujeitos envolvidos.

É nesse sentido que Gallo (2013) problematiza e desloca a terceira característica de uma literatura menor, a saber, seu valor coletivo. Se, em uma literatura menor, tudo diz respeito ao seu agenciamento coletivo, por sua vez, em uma educação menor é a composição das práticas menorizadas dos sujeitos envolvidos que contornam e conduzem tal perspectiva relacionável ao seu valor singular. Não entendendo singular como a individualidade pura e estanque daquilo que perpassa somente o lance biográfico. A singularidade em Deleuze e Guattari (2002) é entendida sempre como relacional, como singularização coletiva.

Por fim, a terceira característica é o valor coletivo. Na educação menor todo ato adquire um valor coletivo. $\mathrm{O}$ educador-militante, ao escolher sua atuação na escola, estará escolhendo para si e para todos aqueles com os quais irá trabalhar. $\mathrm{Na}$ educação menor, não há a possibilidade de atos solitários, isolados; toda ação implicará em muitos indivíduos. (GALLO, 2013, p. 68).

Para Gallo (2013), o exercício de uma educação menor é uma aposta na multiplicidade. Segundo Deleuze, o conceito não é a identidade, mas a multiplicidade:

Aqui, os conceitos se acomodam uns aos outros, superpõem uns aos outros, coordenam seus contornos, compõem seus respectivos problemas, pertencem à mesma filosofia, mesmo se tem histórias diferentes. Com efeito, todo conceito, tendo um número finito de componentes, bifurcara sobre outros conceitos, compostos de outra maneira, mas que constituem outras regiões do mesmo plano, que respondem a problemas conectáveis, participam de uma co-criação. (DELEUZE, 2000, p. 27).

É na característica indissociável de uma multiplicidade que o conceito se articula, conecta-se e "remete a outros conceitos" (DELEUZE. 2007, p. 28). E como poderíamos expressar essa multiplicidade em termos do conceito? Por meio do rizoma.

O rizoma surge como uma possibilidade de expressar criativamente o acontecimento, sem retirar-lhe sua característica mais importante: o devir. É uma das características essenciais do universo rizomático, "a substituição do É pelo E; ou, o que dá no mesmo, a substituição do ser pelo devir.”(ZOURABICHVILI, 2004, p. 3).

É nesse sentido que Gallo (2013) reafirma seu pensamento enquanto postura ética e política no campo educativo. Não como algo pronto e acabado, com ares de política normativa e esquematização de controle. Mas, como ato em construção, em devir, que se estabelece em nome de um projeto sempre coletivo, em multiplicidade. 


\section{Considerações Finais}

Para Deleuze e Guattari criar é a única alternativa diante da tarefa de dar mobilidade ao pensamento. Posto isto, a criação conceitual não é somente uma invenção gratuita, mas a manifestação do aspecto das multiplicidades presentes no conceito: aquilo que produz um filósofo em determinado sistema de pensamento não é, em absoluto, algo inteiramente novo, mas a experimentação da pluralidade dos signos. A consciência que alimenta outra consciência na perspectiva das multiplicidades é a criação coletiva e rizomática de uma busca por representar a realidade, por uma intervenção no mundo, pois o jogo das forças políticas e psicossociais não se desenvolvem somente entre indivíduos, mas também nos signos, nas leis, no desejo, nas micropolíticas.

Diante disso, a proposta de uma educação menor, desenvolvida por Silvio Gallo, colabora para pensarmos a educação não somente como espaço de reprodução e depósito desarticulado e deficiente das políticas públicas. Sobretudo, a educação desenvolvida em uma educação menor, é aquela que abraça o desenvolvimento da subjetividade enquanto singularidades dos sujeitos envolvidos, assim como desdobra a atividade do professor como sujeito que desloca e oferece mecanismos para que se produza o novo, o por vir.

\section{Referências}

DELEUZE, G. Conversações. (1972-1990). Tradução Peter Pál Pelbart. Rio de Janeiro: editora $34,2000$.

DELEUZE, G.; GUATTARI, F. Mil platôs, v. 1, São Paulo: Ed. 34, 2009.

Mil platôs-vol. 2. São Paulo: Ed. 34, 1995.

. Mil platôs-vol. 5. São Paulo: Ed. 34, 2012.

Kafka: por uma literatura menor. Tradução de Júlio Castañon Guimarães. Lisboa: Assírio \& Alvim, 2002. ro: Ed. 34, 2007.

O que é a Filosofia? Tradução: Bento Prado Jr. e Alberto Alonso Moñoz. Rio de JaneiDELEUZE, G.; PARNET, C. Diálogos. Trad. Eloisa Araújo Ribeiro. São Paulo: Escuta, 1998.

GALLO, S. O que é Filosofia da Educação: Anotações a partir de Deleuze e Guattari. Revista Perspectiva. Florianópolis. v. 18. n. 34, jul./dez. 2000.

. Deleuze \& a educação. Autêntica, 2003.

LAPOUJADE, D. Deleuze, os movimentos aberrantes. São Paulo: n-1 edições, 2015.

MOREIRA, O. Uma flor brotará do sol de nossas lembranças: por um a(nar)tivismo indígena no Brasil. Pontos de Interrogação, v. 4, n. 2, p. 161-178, 2014.

SILVA, T. T. Currículo como fetiche: a poética e a política do texto curricular. 1. ed. Belo Horizonte: Autêntica, 2010.

SCHOLLHAMMER, K. E. As práticas de uma língua menor: reflexões sobre um tema de Deleuze e Guattari. Ipotesi, Juiz de Fora, v. 5, n. 2, p. 59-70, 2001.

WEISSMANN, D. Le discours sur la 'littérature mineure': genèse, transferts et limites d'un concept. In: ZEKRI, C.; RODRIGUEZ, B. (Orgs.). La notion de “mineur" entre littérature, arts et politique. Paris: Michel Houdiard, 2012, p. 33-42. 
ZOURABICHVILI, F. Une philosophie de l'événement. Paris: Presses Universitaires de France, 2009.

O vocabulário de Deleuze. Tradução André Telles. Rio de Janeiro 2004.

\section{Notas}

${ }^{1}$ Deleuze e Guattari usam o termo "toca” em Kafka-por uma literatura menor, para exemplificar as múltiplas entradas em uma obra literária rizomática.

${ }^{2}$ Kafka, Franz. Journal. Trans. Marthe Robert. Paris: Grasset, 1954.

${ }^{3}$ Cf.: Weissmann, Dirk. De Kafka à la théorie postcolonial: l'invention de la « littérature mineure. In: SCHWERTER. Stephanie; DICK, Jennifer K.(ORG). Traduire, transmettre ou trahir. Lectures, Les comptes rendus, 2013. p.6.

${ }^{4}$ Para aprofundar a noção do desejo como representação territorial do indivíduo veja O Anti-Édipo e Mil Platôs. Vol. III do mesmo autor.

${ }^{5}$ Cf.: Deleuze, G.Kafka: Por uma literatura menor, 2002, p.89

${ }^{6}$ Sobre sociedade disciplinar, veja "Vigiar e Punir" de Michel Foucault

* Professora da Universidade Estadual de Feira de Santana, Feira de Santana, Bahia, Brasil.

\section{Correspondência}

Francis Mary Soares Correia da Rosa - Secretaria de Educação do Estado da Bahia. 2a Avenida Centro Administrativo da Bahia, Centro Administrativo da Bahia, CEP: 41745-003 - Salvador, Bahia - Brasil.

E-mail: francismrosa@hotmail.com

Recebido em 06 de julho de 2016

Aprovado em 03 de agosto de 2016 
